\title{
Prevalence of Aggressive or Violent Behaviour in Thai Patients with Schizophrenia: a Cross- Sectional Study
}

\author{
N Maneeton, B Maneeton, N Jaiyen, P Woottiluk, W Khemawichanurat
}

\begin{abstract}
Objective: This study aimed to determine the prevalence of violence and factors associated with aggressive or violent behaviour in Thai patients with schizophrenia.

Methods: This cross-sectional study was conducted in all patients with schizophrenia aged $\geq 18$ years admitted to Suan Prung Psychiatric Hospital, Thailand, between January and November 2014. Baseline interviews were conducted by a psychiatrist and psychiatric nurses. Accessibility to weapons and toxic chemicals was evaluated.

Results: Of 230 patients with schizophrenia screened, 207 (162 men and 45 women) were included. Of them, only $16(7.7 \%)$ patients had aggressive or violent behaviour, including verbal aggression $(n=7)$, physical aggression $(n=5)$, and aggression against property $(n=4)$. Nonetheless, only $2(12.5 \%)$ of them had been charged by the police. The weapon score was higher in violent than non-violent patients $(\mathrm{p}<$ $0.05)$. Binary logistic regression analysis showed that the weapon score was the only significant predictor of violence.

Conclusion: Patients with schizophrenia with greater access to weapons were more likely to have aggressive or violent behaviour. Routine screening for access to weapons in clinical settings and adequate treatment of psychotic symptoms may reduce the incidence of aggressive or violent behaviour and violent offences.
\end{abstract}

Key words: Schizophrenia; Violence

Narong Maneeton, MD, FRCPsychT, Department of Psychiatry, Faculty of Medicine, Chiang Mai University, Chiang Mai, Thailand.

Benchalak Maneeton, MD, FRCPsychT, Department of Psychiatry, Faculty of Medicine, Chiang Mai University, Chiang Mai, Thailand.

Natthanan Jaiyen, MS (forensic), The Graduate School Chiang Mai University, Chiang Mai University, Chiang Mai, Thailand

Pakapan Woottiluk, APPMHN, MNS, RN, Psychiatric Nursing Division, Faculty of Nursing, Chiang Mai University, Chiang Mai, Thailand

Wajana Khemawichanurat, MD, FRCPsychT, Suan Prung Psychiatric Hospital, Chiang Mai, Thailand

Address for correspondence: $\mathrm{Dr}$ Benchalak Maneeton, Department of Psychiatry, Faculty of Medicine, Chiang Mai University, Chiang Mai, Thailand. Email:benchalak.maneeton@сти.ac.th

Submitted: 20 December 2017; Accepted: 30 May 2018

\section{Introduction}

Patients with schizophrenia may experience distress, delusion, hallucination, and disorganised speech and behaviour. The rates of aggressive or violent behaviours and criminal offences have been reported to be higher among patients with schizophrenia than in the general population..$^{1-9}$ People with schizophrenia are 20-times more likely than the general population to commit homicide. ${ }^{10}$ Approximately 1 in 600 patients with schizophrenia commit homicide prior to treatment, and the rate of homicide after antipsychotic treatment is about one in 10000 patients per year. ${ }^{11}$
Aggressive or violent behaviour in patients with schizophrenia may be a response to psychotic delusions (especially paranoid or persecutory delusions), hallucinations, or misperceptions, and therefore a psychotic form of self-defense. ${ }^{12}$ Factors associated with aggressive or violent behaviours in patients with schizophrenia include severity of psychotic symptoms, personality dimensions, substance abuse, and mentalising abilities, ${ }^{13,14}$ whereas sociodemographic risk factors include economic deprivation ${ }^{15}$ and social living status. ${ }^{16}$

There are few studies on factors associated with aggressive development, especially in Asian patients with schizophrenia. This study aimed to identify factors associated with aggressive or violent behaviour in Thai patients with schizophrenia.

\section{Methods}

The study was approved by the Ethics Committee of Faculty of Medicine, Chiang Mai University (EC/MEDCMU- PSY2556-01814) and the Ethics Committee of Suan Prung Psychiatric Hospital (EC/SPPH-17-2556). Informed consent was obtained from each participant. This cross-sectional study was conducted in the largest mental health hospital in northern Thailand. All inpatients with schizophrenia aged $\geq 18$ years admitted between January and November 2014 were screened for eligibility. Those who were diagnosed 
with any type of schizophrenia and received any treatment (antipsychotic drugs, electroconvulsive therapy, and/ or supportive therapies) were included. Those who did not provide informed consent, refused to cooperate, or had other psychiatric disorders (schizoaffective disorder, bipolar disorder, major depressive disorder with psychotic feature, or delusional disorder) were excluded, as were those with severe medical conditions such as severe alcohol withdrawal syndrome or temporal lobe epilepsy.

Baseline interviews were conducted by a psychiatrist and psychiatric nurses. Demographic data such as sex, age, educational level, marital status, occupation, income, duration and type of schizophrenia, and treatment were collected. Patient characteristics were collected from the patients themselves, their relatives, and medical records. The diagnosis of schizophrenia was based on the MiniInternational Neuropsychiatric Interview, Thai Version 5.0.0, a short structured diagnostic interview, and the DSM IV-TR, whereas the severity of comorbidities was measured using the Charlson comorbidity index..$^{17}$

Violence includes threats and verbal aggression, aggression against property, self-harming behaviour, and physical aggression. ${ }^{11,18}$ The psychosocial aspects potentially leading to aggressive or violent behaviour include relationships between patients and others (neighbours, coworkers, or family members), public reprimand or blame, forced treatment or medication, criticism from others (family members, relatives, friends, neighbours, or co-workers), and home and community environments. ${ }^{11}$ Accessibility to weapons and toxic chemicals was evaluated; higher scores indicated higher risk of accessing weapons/toxic chemicals. History of being charged by the police with a criminal offence or convicted in a court of a criminal offence was collected.

In a previous study, the prevalence of aggressive or violent behaviour in patients with schizophrenia admitted to remand prison was $6.1 \%(166 / 2743) .{ }^{3}$ The sample size required to make calculations with a $95 \%$ confidence interval was calculated as 88 patients; therefore, we planned to recruit 200 patients. To identify factors associated with aggressive or violent behaviour, violent and non-violent patients were compared using $t$-test or the Mann-Whitney $U$ test (for continuous variables) and Fisher's exact test or $\chi^{2}$ test (for categorical variables). A binary logistic regression model was applied to identify predictors of aggressive or violent behaviour. Significant independent variables $(\mathrm{p}<$ $0.05)$ and covariates $(\mathrm{p}<0.20)$ at the bivariate level were included. All statistical analyses were carried out using SPSS (Windows version 22; IBM Corp, Armonk [NY], US)

\section{Results}

Of the 230 patients with schizophrenia screened, 23 were excluded owing to incomplete data, and 207 (162 men and 45 women) with a mean age of $38.7 \pm 10.3$ years were included (Figure). Of the 207 patients, 67.6\% were single; they had a mean of $7.7 \pm 3.8$ years of education; $36.7 \%$ were unemployed; and therefore, their income was low. 142 $(68.6 \%)$ had been diagnosed with paranoid schizophrenia and had the condition for a mean of $7.0 \pm 7.7$ years; 63 $(30.4 \%)$ were treated with electroconvulsive therapy; and $35(16.9 \%)$ had suicidal risk. Only $16(7.7 \%)$ of patients had aggressive or violent behaviour, including verbal aggression $(n=7)$, physical aggression $(n=5)$, and aggression against property $(n=4)$. Nonetheless, only $2(12.5 \%)$ of them had been charged by the police.

Violent and non-violent patients were comparable in terms of sex, age, years of schooling, marital status, occupation, personal and household income, and duration and type of schizophrenia. However, the weapon score was higher in violent patients $(\mathrm{p}<0.05$, Table 1$)$. The binary logistic regression analysis showed that the weapon score was the only significant predictor of violence (adjusted $R^{2}=$ 0.172 , standard error of the estimate $=0.034$, Wald $=4.197$, Table 2).

\section{Discussion}

In the present study, only $16(7.7 \%)$ patients with schizophrenia had aggressive or violent behaviour, mostly verbal aggression. Of them, only $2(12.5 \%)$ were charged by the police for violent offenses. However, neither of those was convicted in court. The risk of aggressive or violent behaviour was significantly higher in patients with higher access to weapons.

The prevalence of violent offences is greater in patients with schizophrenia than in normal populations. A case-control study reported that the lifetime and 5-year prevalence of violent offence in patients with schizophrenia after the first admission was $8.2 \%$ and $3.0 \%$, respectively, compared with $1.8 \%$ and $0.4 \%$ in controls. ${ }^{1}$ Similarly, a meta-analysis found that $9.9 \%$ of patients with schizophrenia and other psychotic conditions were violent, compared with $1.6 \%$ of the general population. ${ }^{10}$

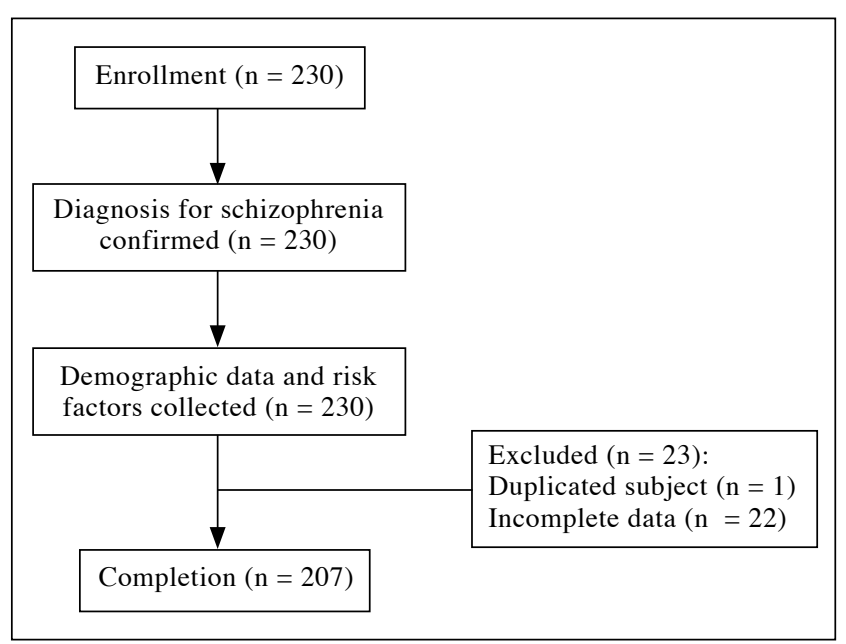

Figure. Flow diagram of enrollment and completion of participants. 
Table 1. Demographic data of patients with schizophrenia.

\begin{tabular}{|c|c|c|c|}
\hline Factor & $\begin{array}{l}\text { Non-violent } \\
(\mathbf{n}=191)^{*}\end{array}$ & $\begin{array}{l}\text { Violent } \\
(\mathbf{n}=16)^{*}\end{array}$ & p Value \\
\hline \multicolumn{4}{|l|}{ Sex } \\
\hline Male & $151(72.9)$ & $12(5.8)$ & 0.751 \\
\hline Female & $40(19.4)$ & 4 (1.9) & \\
\hline Age, $y$ & $38.4 \pm 10.2$ & $42.3 \pm 11.2$ & 0.201 \\
\hline Years of schooling & $7.7 \pm 3.7$ & $7.0 \pm 4.7$ & 0.571 \\
\hline Educational level & & & 0.118 \\
\hline Uneducated & $16(7.7)$ & $3(1.4)$ & \\
\hline 1-6 years & $81(39.1)$ & $6(2.9)$ & \\
\hline $7-9$ years & $51(24.6)$ & $1(0.5)$ & \\
\hline 10-12 years & $29(14.0)$ & $4(1.9)$ & \\
\hline$\geq 13$ years & $14(6.8)$ & $2(1.0)$ & \\
\hline Marital status & & & 0.619 \\
\hline Married & $31(15.0)$ & $3(1.4)$ & \\
\hline Single & $130(62.8)$ & $10(4.8)$ & \\
\hline Divorced/separated & $25(12.1)$ & $2(1.0)$ & \\
\hline Widow & $5(2.4)$ & $1(0.5)$ & \\
\hline Occupation & & & 0.885 \\
\hline Unemployed & $68(32.9)$ & $8(3.9)$ & \\
\hline Employee & $74(35.7)$ & $5(2.4)$ & \\
\hline Owner & $11(5.3)$ & $1(0.5)$ & \\
\hline Government officer & $1(0.5)$ & $0(0)$ & \\
\hline Agriculture & $29(14.0)$ & $2(1.0)$ & \\
\hline Monk & $7(3.4)$ & $0(0)$ & \\
\hline Student & $1(0.5)$ & $0(0)$ & \\
\hline $\begin{array}{l}\text { Annual personal } \\
\text { income, US\$ }\end{array}$ & $1643 \pm 3092$ & $1616 \pm 1765$ & 0.715 \\
\hline $\begin{array}{l}\text { Annual household } \\
\text { income, US\$ }\end{array}$ & $3320 \pm 4556$ & $2443 \pm 2873$ & 0.314 \\
\hline $\begin{array}{l}\text { Duration of } \\
\text { schizophrenia, y }\end{array}$ & $7.2 \pm 7.7$ & $5.3 \pm 6.7$ & 0.350 \\
\hline $\begin{array}{l}\text { Received } \\
\text { electroconvulsive } \\
\text { therapy }\end{array}$ & $61(29.5)$ & $2(1.0)$ & 0.156 \\
\hline Having suicidal risk & $34(16.4)$ & $1(0.5)$ & 0.318 \\
\hline Type of schizophrenia & & & 0.463 \\
\hline Paranoid & $133(64.3)$ & $9(4.3)$ & \\
\hline Disorganized & $2(1.0)$ & $0(0)$ & \\
\hline Catatonic & $1(0.5)$ & $0(0)$ & \\
\hline Undifferentiated & $54(26.1)$ & $7(3.4)$ & \\
\hline Unspecified & $1(0.5)$ & $0(0)$ & \\
\hline $\begin{array}{l}\text { Charlson comorbidity } \\
\text { index score }\end{array}$ & $0.1 \pm 1.5$ & $0.3 \pm 1.0$ & 0.190 \\
\hline Nicotine use & $71(34.3)$ & $5(2.4)$ & 0.637 \\
\hline Alcohol use & $17(8.2)$ & $0(0)$ & 0.372 \\
\hline Amphetamine use & $6(2.9)$ & $2(1.0)$ & 0.119 \\
\hline $\begin{array}{l}\text { Poor relationships with } \\
\text { neighborhood(s) or } \\
\text { workmate(s) }\end{array}$ & $46(22.2)$ & $7(3.4)$ & 0.131 \\
\hline $\begin{array}{l}\text { Poor relationships with } \\
\text { family member(s) }\end{array}$ & $39(18.8)$ & $2(1.0)$ & 0.744 \\
\hline $\begin{array}{l}\text { Patients reprimanded or } \\
\text { blamed in public }\end{array}$ & $37(17.9)$ & $3(1.4)$ & 1.000 \\
\hline
\end{tabular}

Data are presented as mean \pm standard deviation or No. (\%) of participants.
Table 1. (cont'd)

\begin{tabular}{|lccc|}
\hline Factor & $\begin{array}{c}\text { Non-violent } \\
(\mathbf{n}=191)^{*}\end{array}$ & $\begin{array}{c}\text { Violent } \\
(\mathbf{n = 1 6})^{*}\end{array}$ & $\mathbf{p ~ V a l u e}$ \\
$\begin{array}{l}\text { Patients often subjected } \\
\text { to forced treatment }\end{array}$ & $52(25.1)$ & $7(3.4)$ & 0.162 \\
\hline $\begin{array}{l}\text { Patients subjected to } \\
\text { forced medication }\end{array}$ & $54(26.1)$ & $7(3.4)$ & 0.252 \\
\hline $\begin{array}{l}\text { Patients criticised by } \\
\text { family member(s) or } \\
\text { others }\end{array}$ & $39(18.8)$ & $5(2.4)$ & 0.341 \\
\hline $\begin{array}{l}\text { Poor housing and home } \\
\text { conditions }\end{array}$ & $31(15.0)$ & $3(1.4)$ & 0.731 \\
\hline $\begin{array}{l}\text { Improper environmental } \\
\text { conditions }\end{array}$ & $29(14.0)$ & $4(1.9)$ & 0.293 \\
\hline Weapon score & $18.0 \pm 8.7$ & $23.6 \pm 8.1$ & 0.021 \\
\hline
\end{tabular}

Substance use disorder is associated with aggressive or violent behaviour in patients with schizophrenia, ${ }^{1,10,19-23}$ as are personality co-morbidities, particularly antisocial personality trait or disorder. ${ }^{24,25}$ However, in Japanese patients with schizophrenia, violent behaviour is related to schizophrenic symptoms rather than antisocial traits or substance use disorder. ${ }^{13}$ Similarly, the present study showed no association of substance use disorder or personality traits or disorders with schizophrenia in our patients. Rather, aggressive or violent behaviour may be caused by several factors before, during, and after periods of active illness and may be affected by cultural and racial diversity. ${ }^{1,13}$

The present study had some limitations. The sample size was small; a larger sample is needed to confirm these findings. All patients with schizophrenia were hospitalised, and their factors for developing aggressive or violent behaviour may differ from those of other non-hospitalised patients or patients with other psychotic conditions. Thus, the findings should only be generalised with caution. Cultural differences may influence the development of aggressive or violent behaviour in Thai patients with schizophrenia, and the findings may not be generalisable to other populations. Some patients who had committed acts of severe violence or homicide were imprisoned, and this may have also affected the prevalence of aggressive or violent behaviour that we found.

\section{Conclusion}

Thai patients with schizophrenia who had higher access to weapons were more likely to have aggressive or violent behaviour. Routine screening for access to weapons in clinical settings and adequate treatment of psychotic symptoms may reduce the incidence of aggressive or violent behaviour and violent offences.

\section{Funding}

This work was supported by the Faculty of Medicine, 
Table 2. Binary logistic regression analysis of predictors for aggression/violence in patients with schizophrenia.

\begin{tabular}{|lccccc|}
\hline Co-variable & $\boldsymbol{\beta}$ & $\begin{array}{c}\text { Standard } \\
\text { error }\end{array}$ & Wald & $\begin{array}{c}\text { Odds ratio }(95 \% \\
\text { confidence interval) }\end{array}$ & p Value \\
Uneducated & 0.761 & 0.745 & 1.044 & $2.140(0.497-9.211)$ & 0.307 \\
\hline Electroconvulsive therapy & -1.002 & 0.804 & 1.554 & $0.367(0.076-1.774)$ & 0.213 \\
\hline Charlson comorbidity index & 0.078 & 0.139 & 0.316 & $1.081(0.824-1.419)$ & 0.574 \\
\hline Amphetamine use & 1.394 & 0.964 & 2.093 & $4.032(0.610-26.670)$ & 0.148 \\
\hline Poor relationships & 0.980 & 0.613 & 2.553 & $2.664(0.801-8.858)$ & 0.110 \\
\hline Patients with forced treatment & 0.486 & 0.599 & 0.659 & $1.626(0.503-5.256)$ & 0.417 \\
\hline Weapon score & 0.070 & 0.034 & 4.197 & $1.073(1.003-1.148)$ & 0.041 \\
\hline Constant & -4.451 & 0.923 & 23.258 & 0.012 & 0.000 \\
\hline
\end{tabular}

Chiang Mai University (046/2557) and Chiang Mai University (04/2562).

\section{Declaration}

Narong Maneeton has received travel reimbursement from Lundbeck and Pfizer. Benchalak Maneeton has been an advisory board member of Pfizer and received honoraria and/or travel reimbursement from Lundbeck, Servier, and Pfizer. Natthanan Jaiyen, Pakapan Woottiluk, and Wajana Khemawichanurat report no conflicts of interest.

\section{References}

1. Wallace C, Mullen PE, Burgess P. Criminal offending in schizophrenia over a 25 -year period marked by deinstitutionalization and increasing prevalence of comorbid substance use disorders. Am J Psychiatry 2004;161:716-27. Crossref

2. Soyka M, Graz C, Bottlender R, Dirschedl P, Schoech H. Clinical correlates of later violence and criminal offences in schizophrenia. Schizophr Res 2007;94:89-98. Crossref

3. Taylor PJ, Gunn J. Violence and psychosis. I. Risk of violence among psychotic men. Br Med J (Clin Res Ed) 1984;288:1945-9. Crossref

4. Kay SR, Wolkenfeld F, Murrill LM. Profiles of aggression among psychiatric patients. II. Covariates and predictors. J Nerv Ment Dis 1988;176:547-57. Crossref

5. Morgan VA, Morgan F, Valuri G, Ferrante A, Castle D, Jablensky A. A whole-of-population study of the prevalence and patterns of criminal offending in people with schizophrenia and other mental illness. Psychol Med 2013;43:1869-80. Crossref

6. Bo S, Abu-Akel A, Kongerslev M, Haahr UH, Simonsen E. Risk factors for violence among patients with schizophrenia. Clin Psychol Rev 2011;31:711-26. Crossref

7. Ran MS, Chen PY, Liao ZG, Chan CL, Chen EY, Tang CP, et al. Criminal behavior among persons with schizophrenia in rural China. Schizophr Res 2010;122:213-8. Crossref

8. Brennan PA, Mednick SA, Hodgins S. Major mental disorders and criminal violence in a Danish birth cohort. Arch Gen Psychiatry 2000;57:494-500. Crossref

9. Kosger F, Essizoglu A, Sonmez I, Gulec G, Genek M, Akarsu O. The relationship between violence and clinical features, insight and cognitive functions in patients with schizophrenia [in Turkish]. Turk Psikiyatri Derg 2016;27:0. Crossref

10. Fazel S, Gulati G, Linsell L, Geddes JR, Grann M. Schizophrenia and violence: systematic review and meta-analysis. PLoS Med 2009;6:e1000120. Crossref

11. Large MM, Nielssen O. Violence in first-episode psychosis: a systematic review and meta-analysis. Schizophr Res 2011;125:20920. Crossref

12. Coid JW, Ullrich S, Bebbington P, Fazel S, Keers R. Paranoid ideation and violence: meta-analysis of individual subject data of 7 population surveys. Schizophr Bull 2016;42:907-15. Crossref

13. Imai A, Hayashi N, Shiina A, Sakikawa N, Igarashi Y. Factors associated with violence among Japanese patients with schizophrenia prior to psychiatric emergency hospitalization: a case-controlled study. Schizophr Res 2014;160:27-32. Crossref

14. Douglas KS, Guy LS, Hart SD. Psychosis as a risk factor for violence to others: a meta-analysis. Psychol Bull 2009;135:679-706. Crossref

15. Modestin J, Ammann R. Mental disorder and criminality: male schizophrenia. Schizophr Bull 1996;22:69-82. Crossref

16. Swanson JW, Van Dorn RA, Swartz MS, Smith A, Elbogen EB, Monahan J. Alternative pathways to violence in persons with schizophrenia: the role of childhood antisocial behavior problems. Law Hum Behav 2008;32:228-40. Crossref

17. Charlson ME, Pompei P, Ales KL, MacKenzie CR. A new method of classifying prognostic comorbidity in longitudinal studies: development and validation. J Chronic Dis 1987;40:373-83. Crossref

18. Kay SR, Wolkenfeld F, Murrill LM. Profiles of aggression among psychiatric patients. I. Nature and prevalence. J Nerv Ment Dis 1988;176:539-46. Crossref

19. Grann M, Danesh J, Fazel S. The association between psychiatric diagnosis and violent re-offending in adult offenders in the community. BMC Psychiatry 2008;8:92. Crossref

20. Elbogen EB, Johnson SC. The intricate link between violence and mental disorder: results from the National Epidemiologic Survey on Alcohol and Related Conditions. Arch Gen Psychiatry 2009;66:15261. Crossref

21. Mullen PE. A reassessment of the link between mental disorder and violent behaviour, and its implications for clinical practice. Aust N Z J Psychiatry 1997;31:3-11. Crossref

22. Scott H, Johnson S, Menezes P, Thornicroft G, Marshall J, Bindman J, et al. Substance misuse and risk of aggression and offending among the severely mentally ill. Br J Psychiatry 1998;172:345-50. Crossref

23. Smith J, Hucker S. Schizophrenia and substance abuse. Br J Psychiatry 1994;165:13-21. Crossref

24. Bo S, Abu-Akel A, Kongerslev M, Haahr UH, Simonsen E. The role of co-morbid personality pathology in predicting self-reported aggression in patients with schizophrenia. Compr Psychiatry 2013;54:423-31. Crossref

25. Newton-Howes G, Tyrer P, North B, Yang M. The prevalence of personality disorder in schizophrenia and psychotic disorders: systematic review of rates and explanatory modelling. Psychol Med 2008;38:1075-82. Crossref 